\title{
EFFECT OF SILICON CARBIDE PERCENTAGE ON FRACTURE TOUGHNESS OF ALUMINIUM SILIOCN CARBIDE METAL MATRIX COMPOSITES
}

\author{
Nidhish B N $\mathbf{N}^{1}$, Sijo M T $\mathbf{T}^{2}$ \\ ${ }^{I}$ PG Scholar, Mechanical Engineering Department, SCMS School of Engineering and Technology, Kerala, India \\ ${ }^{2}$ PhD Scholar, Govt Engineering College, Thrissur, Kerala, India
}

\begin{abstract}
Metal matrix composites are composites in which one component will be a metal and other metal or non metal. It has wide applications in various fields like automobile, turbines blades etc which needs good mechanical properties. This thesis work studies about Aluminium Silicon Carbide metal matrix composites and their properties. Earlier studies revealed that as the percentage of Silicon Carbide is increased the properties get increased up to a limit and fracture toughness gets reduced beyond that. Here, in this work different percentage of SiC is added and fracture toughness is analyzed in terms of Stress intensity factor since fracture toughness cannot be calculated directly. Both software simulation and experimental methods has been done to find out the best percentage composition.
\end{abstract}

Keywords: Metal matrix composites, Aluminium Silicon Carbide, Fracture Toughness, Stress Intensity Factor

\section{INTRODUCTION}

A metal matrix composite (MMC) is composite material with at least two constituent parts, one being a metal. The other material may be a different metal or another material, such as a ceramic or organic compound. When at least three materials are present, it is called a hybrid composite.

Researches shows decrease in value of critical properties like hardness, fracture toughness on the addition of micro particle composition at higher amounts. Fracture toughness is the ability of the material to withstand failure due to crack propagation. Earlier, studies had been done on $\mathrm{Mg}-\mathrm{SiC}$ metal matrix composites. Aluminium having better properties need to be analyzed. Fracture toughness, ductility etc are important mechanical properties regarding a metal matrix composite.

From the previous studies it is clear that on addition of Silicon carbide essential properties of metal matrix composites will get boosted. If the material has ductile feature it will be having higher fracture toughness which is the ability to resist crack propagation. If the material tends to be more brittle it will be having less fracture toughness. But the properties get boosted up to a limit and at high amount of addition of $\mathrm{SiC}$ show that the properties of the metal matrix composites are getting reduced. This study is done in order to find the percentage of Silicon Carbide so that to get maximum fracture toughness.

\section{LITERATURE REVIEW}

Paragraph comes content here. According to matrix constituent, composites are classified into organic-matrix composites, metal matrix composites (MMCs) and ceramic- matrix composites. Among these composites, MMCs provide significantly enhanced properties such as higher strength, specific modulus, damping capacity, stiffness, good wear resistance and weight savings. The major disadvantage of MMC usually lies in the relatively high cost of fabrication and of the reinforcement materials. In terms of shape, the reinforcement material may be sub-divided into four major category (i) continuous fibres, (ii) Short fibres (chopped fibres are not necessarily all the same length) (iii) Whiskers (iv) Particles. Among various reinforcements particles are the most common and cheapest reinforcement.

While continuous fiber reinforcement MMCs provide the most effective strengthening (in a given direction), particle reinforced MMCs are more attractive due to their costeffectiveness, isotropic properties, and their ability to be processed using similar technologies which are used for the monolithic materials. Among various matrix materials, aluminium alloy matrix materials possess high tensile strength, good corrosion resistance etc. Similarly among various reinforcements silicon carbide reinforcements are inexpensive; improve yield strength and elastic modulus at little expense of ductility. Silicon carbide as such, because of its high hardness, has got a number of applications such as in cutting tools, jewellery, automobile parts, electronic circuits, structural materials, nuclear fuel particles, etc. Like all composites, aluminum-matrix composites are not a single material but a family of materials whose stiffness, strength, density, thermal and electrical properties can be tailored. The Al-SiC MMC possess wide range of physical and mechanical properties such as high strength, stiffness, low density, high corrosion, wear resistance, low thermal shock, high electrical, thermal conductivity, good thermal properties and good damping capability. Among all 
materials, composite materials have the potential to replace widely used steel and aluminum, and many times with better performance. $\mathrm{Al}-\mathrm{SiC} \mathrm{MMC}$ are used in various fields like aerospace, fuselage skins of high performance aircrafts, underwater, automobile, substrate in electronics, golf clubs, turbine blades, brake pads etc.

The manufacturing methods available for Al-SiC MMC can be broadly classified into three types. They are solid phase process such as powder metallurgy and diffusion bonding, liquid phase process such as stir casting, infiltration of liquid matrix into the reinforcements and in situ processes, and semisolid method such as spray and rehocasting and compo casting[4]. Of these manufacturing methods, stir casting is found to have moderate properties like low cost, ability to make in different shape and size etc[2].

\section{RESEARCH PROBLEM AND OBJECTIVE}

Research problem is that on addition of $\mathrm{SiC}$ on metal matrix composites on higher amounts shown reduction in properties like fracture toughness. Since metal matrix composites have wider applications which require higher fracture toughness which is the ability to resist failure due to crack propagation.

The objective of this work is to find the best percentage of Silicon carbide that will yield higher fracture toughness. For this different iterations are to be done using software analysis and experimental methods. Since, fracture cannot be calculated directly, stress intensity factor which is a good indicator of fracture toughness is calculated and the percentage of Silicon carbide at which highest stress intensity factor is obtained is to be found out.

\section{METHODOLOGY}

Paragraph comes content here. The research work has been done experimentally using a stir casting furnace and the process has been simulated using an analysis software. Since, fracture toughness cannot be found directly stress intensity factor is found out.

\subsection{Experimental Method}

The step by step has been followed. Stir casting process starts with placing empty crucible in the muffle. At first heater temperature is set to $500^{\circ} \mathrm{C}$ and then it is gradually increased up to $900^{\circ} \mathrm{C}$. High temperature of the muffle helps to melt aluminium quickly, reduces oxidation level, enhance the wettability of the reinforcement particles in the matrix metal. Required quantity of aluminium alloy is taken cleaned to remove dust and poured into the crucible. Silicon carbide will be preheated to remove moisture and it will be added continuously into the molten aluminium as reinforcement. Reinforcements are heated for half hour and at temperature of $500^{\circ} \mathrm{C}$. When matrix was in the fully molten condition, Stirring is started after 2 minutes. Stirrer rpm is gradually increased from 0 to 300 RPM with the help of speed controller. Silicon carbide is then allowed to fall into the molten aluminium in a uniform rate. Silicon carbide is taken in quantity as to make different proportions or percentages. Temperature of the heater is set to $630^{\circ} \mathrm{C}$ which is below the melting temperature of the matrix.

A uniform semisolid stage of the molten matrix was achieved by stirring it at $630^{\circ}$ C.Pouring of preheated reinforcements at the semisolid stage of the matrix enhance the wettability of the reinforcement, reduces the particle settling at the bottom of the crucible. Dispersion time were taken as 5 minutes. After stirring 5 minutes at semisolid stage slurry was reheated and hold at a temperature $900^{\circ} \mathrm{C}$ to make sure slurry is in liquid state. Stirrer RPM was then gradually lowered to the zero. The stir casting apparatus is manually kept side and then molten composite slurry is poured in the metallic mould. Mould is preheated at temperature $500^{\circ} \mathrm{C}$ before pouring of the molten slurry in the mould. This makes sure that slurry is in molten condition throughout the pouring. While pouring the slurry in the mould the flow of the slurry is kept uniform to avoid trapping of gas. Then it is quenched with the help of air to reduce the settling time of the particles in the matrix and to avoid oxidation.

As the material for testing is aluminium and fracture toughness is to be tested, American Society for Testing Material standard was made. ASTM E399 standard is standard used for testing toughness of materials. Standard size for the test piece is calculated and mould is prepared. After the composite is made by stir casting and is at right temperature for pouring, the slurry is then poured into the mould which is preheated so that the chance for trapping gas in between the casting is reduced. The casted test piece is then allowed to cool normally at room temperature. The manufactured piece is then shaped by removing the additions and shaping it to the required dimension.

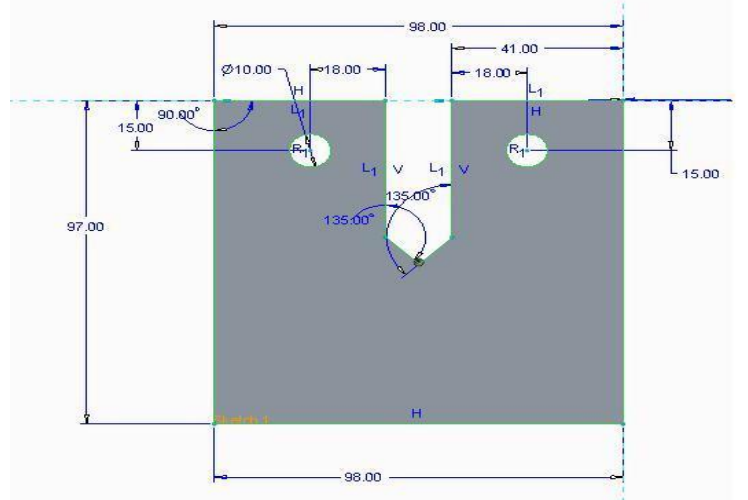

Fig -1: Standard E399 test piece

After the test piece is being made it is to be tested for finding fracture toughness. As fracture toughness cannot be found directly as a value, we will be finding the maximum load that the test pieces will resist the crack propagation without failure. Groove will act as an initial crack. As per the definition for fracture toughness is the ability of a material which is having a crack to resist the propagation of the crack. In the test piece prepared there is initial crack and we will apply load so as to find till what load it can withstand without failure. Universal Testing Machine is 
used for testing. The jaws for clamping the required test piece are setted up in the testing machine and test pieces are clamped on to the machine. After setting the test piece properly, the load is given. By gradual loading the load at which test piece fails to resist crack is found out and recorded. The value is noted for all iterations.

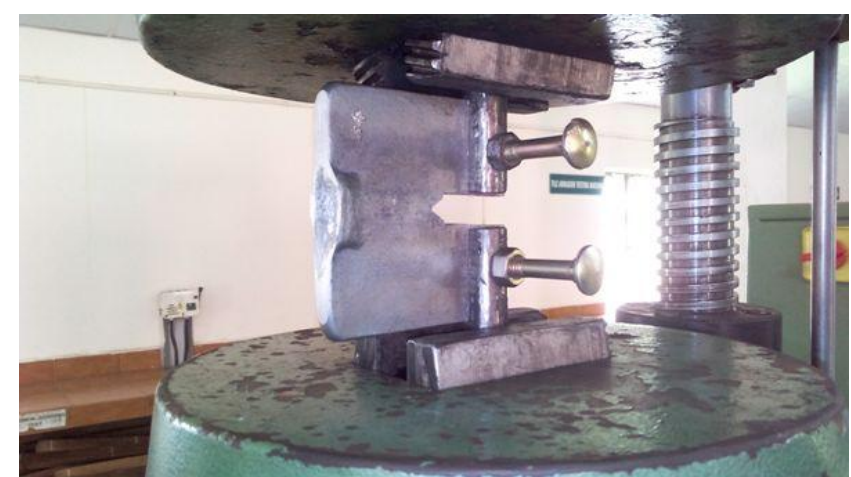

Fig -2: Standard Test piece being tested in Universal Testing Machine

\subsection{Simulation Method.}

Simulation method is done using an analysis software and the following steps are done :-Build the 3D model in modeling software. Import the model to the analysis software using surface extraction. Give the properties according to the graphs of different proportions of SiC. Load analysis is done on the model after giving the constraints. Run the analysis. Stress intensity factor is found from list results by selecting the nodes. The process is repeated for varying proportions of Silicon carbide.

\section{RESULTS AND DISCUSSIONS}

The results for experimental method has to be calculated using the formulae for finding the stress intensity factor, where as it can be directly noted in analysis software for simulation method.

\subsection{Experimental Method.}

Stress intensity factor can be calculated as:

$$
\text { Stress Intensity factor }(\mathrm{KIC})=\frac{\mathrm{P}}{\mathrm{B} * \sqrt{\mathrm{W}}} * \mathrm{f}\left(\frac{\mathrm{a}}{\mathrm{W}}\right)-
$$

Where, $\mathrm{P}=$ maximum load till failure, $\mathrm{B}$ and $\mathrm{W}$ dimensions and $f(a / w)$ is a constant for various $a / w$ ratio. The results obtained for various proportions of Silicon carbide are given in the table-1.

\subsection{Simulation Method}

In simulation method, the stress intensity factor can be directly noted form the post processing section. The results are given in the table- 2 .

From the results, it is clear that highest stress intensity factor is being achieved for $25 \%$ addition of Silicon Carbide in weight in both methods. The value has been increasing till $25 \%$ and on further addition it gets reduced.

Table -1: Results from experimental method

\begin{tabular}{|l|l|l|}
\hline Sl no & $\begin{array}{l}\text { Percentage } \\
\text { of Silicon } \\
\text { Carbide }\end{array}$ & $\begin{array}{l}\text { Stress Intensity } \\
\text { Factor }(\mathrm{MPa} \sqrt{\mathrm{m}})\end{array}$ \\
\hline 1 & 20 & 10.7132 \\
\hline 2 & 25 & 19.0514 \\
\hline 3 & 30 & 15.4717 \\
\hline
\end{tabular}

Table -2: Results from experimental method

\begin{tabular}{|l|l|l|}
\hline Sl no & $\begin{array}{l}\text { Percentage of } \\
\text { Silicon } \\
\text { Carbide }\end{array}$ & $\begin{array}{l}\text { Stress Intensity Factor } \\
(\mathrm{MPa} \sqrt{\mathrm{m}})\end{array}$ \\
\hline 1 & 5 & 7.4164 \\
\hline 2 & 10 & 8.2404 \\
\hline 3 & 15 & 9.0050 \\
\hline 4 & 20 & 11.5372 \\
\hline 5 & 25 & 18.9537 \\
\hline 6 & 30 & 14.833 \\
\hline
\end{tabular}

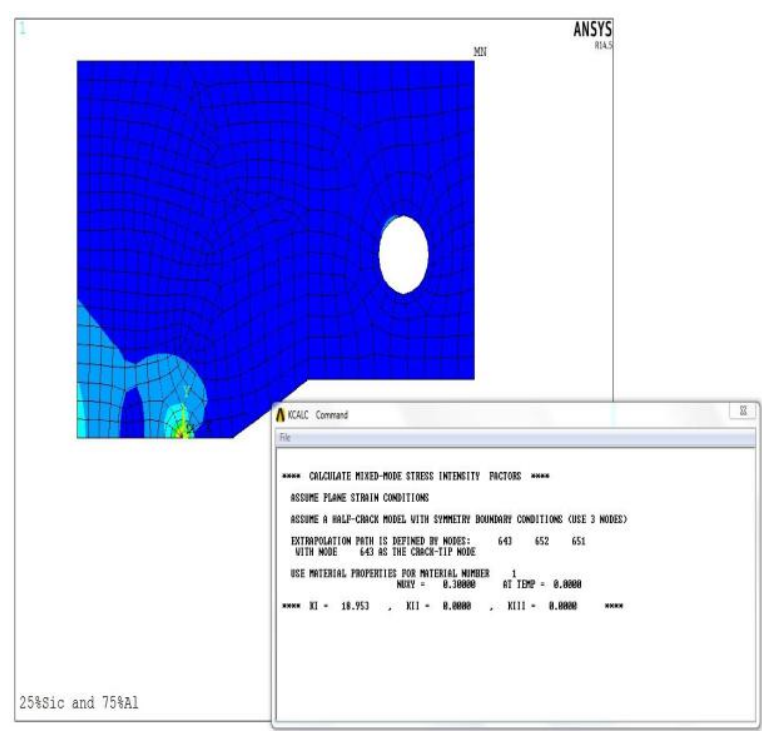

Fig -3: Result for 25\% Silicon carbide addition in simulation method

\section{CONCLUSION}

Paragraph comes content here. The objective of the study was to find the best composition or percentage of Silicon Carbide which will produce higher fracture toughness. Researchers shown that fracture toughness has been reduced on increased addition of Silicon carbide. The work studied the effect of Silicon carbide addition by analyzing the stress intensity factor for various iterations. For testing ASTM E399 standard which is commonly used for testing of fracture toughness is being studied. The analysis has been made in a software and experimentally. Software used is ANSYS and for fabrication stir casting method was used. In 
software methods analysis has been done for 5\%, $10 \%$, $15 \%, 20 \%, 25 \%$ and $30 \%$ of Silicon carbide addition. From software method we get to know the trend of the results and by considering the cost constraints, the experimental methods has been done in $20 \%, 25 \%$ and $30 \%$ of Silicon carbide addition. Both analysis shown that the best results for fracture toughness is at $25 \%$ addition of Silicon carbide. Further addition shown reduction in stress concentration factor and the reasons for reduction is a scope for further research.

\section{ACKNOWLEDGEMENTS}

The satisfaction of having achieved the successful completion of a work would simply be incomplete if the words of gratitude to the great minds that helped in its attainment are not expressed. I would like to thank my guide Mr. Sijo MT and all other staff members from SSET and staff members of Karunya University, Coimbatore for helping me to complete this work.

\section{REFERENCES}

[1]. G.G.Sozhamannan, S.Balasivanandha Prabhu, V.S.K. Venatagalapathy "Effect of Processing parameters on metal matrix composites: stir casting process" Journal of Surface Engineered Materials and Advanced Technology, 2012, 2, 11-15

[2]. Hashim J, Looney L and Hashmi M.S.J, “ Metal Matrix Composites: Production by the Stir Casting Method, Journal of Material Processing and Technology, 92,1999, pp 1-7.

[3]. M K Surappa, "Aluminium matrix composites: Challenges and Opportunities", Sadhana Vol. 28, Parts 1 \& 2, February/April 2003, pp. 319-334.

[4]. Naher, S, Brabazon D and Looney L, "Development and assessment of a new quick quench stir caster design for the production of metal matrix composites", Journal of Material Processing Technology, Vol. 166, 2004, pp 430-439.

[5]. Jayashree P .K, Gowri Shankar M.C , Achutha Kini, Sharma S.S and Raviraj Shetty, "Review on Effect of Silicon Carbide (SiC) on Stir Cast Aluminium Metal Matrix Composites" International Journal of Current Engineering and Technology,2013.

[6]. Rabindra Behera, S.Das, D. Chatterjee, G.Sutradhar "Experimental investigation on the effect of reinforcement particles on the forgeability and the mechanical properties of aluminum metal matrix composites "Materials Sciences and Applications, 2010, 1, 310-316.

[7]. Manoj Singla, D, Deepak Dwivedi1, Lakhvir Singh, Vikas Chawla, "Development of Aluminium Based Silicon Carbide Particulate Metal Matrix Composite" Journal of Minerals \& Materials Characterization \& Engineering, Vol. 8, No.6,2009, pp 455-467.ered Materials and Advanced Technology, 2012, 2, 11-15

[8]. Khalid Mahmood Ghauri, Liaqat Ali, Akhlaq Ahmad, Rafiq Ahmad, Kashif Meraj Din. Ijaz Ahmad Chaudhary, Ramzan Abdul Karim"Synthesis and Characterization of Al/SiC Composite Made by Stir Casting Method" Pak. J. Engg. \& Appl. Sci. Vol. 12, Jan., 2013 pp. 102-110.
[9]. S. Naher, D. Brabazon, L. Looney, " Simulation of the stir casting process" Journal of Materials Processing Technology,2003,pp 567-571.

[10]. Lihe Qian,Toshiro Kobayashi,Hiroyuki Toda,Takashi Goda and Zhong-Guang Wang, "Fracture toughness of a 6061 Al matrix composite reinforced with fine $\mathrm{SiC}$ particles,Materials" Transactions, Vol 43,No 11,2002, pp 2838 - 2842.

[11]. A. Pramanik, L.C. Zhang, J.A. Arsecularatne, "An FEM investigation into the behavior of metal matrix composites:Tool-particle interaction during orthogonal cutting" International Journal of Machine Tools \& Manufacture 47 ,2007, pp 1497-1506

[12]. Srinivasa R. Bakshi, Anup K. Keshri, Virendra Singh, Sudipta Seal, Arvind Agarwal “ Interface in carbon nanotube reinforced aluminum silicon composites:Thermodynamic analysis and experimental verification" Journal of Alloys and Compounds 481, 2009, pp 207-213.

[13]. G.Papakaliatakisd, Karalekas, “ Computational Study of Crack Growth in SiC/A1 Composites"Mathematical and Computer Modelling 42, 2005 , pp 799-808.

[14]. K. L. Meena, Dr. A. Manna, Dr. S. S. Banwait, Dr. Jaswanti, "An Analysis of Mechanical Properties of the Developed Al/SiC-MMC's" American Journal of Mechanical Engineering, 2013, Vol. 1, No. 1,pp 14-19.

[15]. G.B. Veeresh Kumar, C. S. P. Rao, N. Selvaraj, M. S. Bhagyashekar, "Studies on Al6061-SiC and Al7075 A12O3 Metal Matrix Composites"Journal of Minerals \& Materials Characterization \& Engineering, Vol. 9,2010, pp 43-55 